\title{
Further Photo-electric Measurements of the Penetration of Light into Sea-Water.
}

\author{
By \\ H. H. Poole, Sc.D., \\ Chief Scientific Officer of the Royal Dublin Society, \\ And \\ W. R. G. Atkins, Sc.D., F.R.S., \\ Head of the Department of General Physiology at the Plymouth Laboratory.
}

With 1 Plate and 4 Figures in the Text.

\section{INTRODUCTION.}

Descriptions have been given in previous papers (1 and 2 ) of some measurements, carried out during the autumns of 1924 and 1925, on the penetration of light into sea-water near Plymouth; a review has also been given by one of us (3) of previous work on submarine illumination with special reference to plant distribution. Various circumstances combined to prevent the carrying out of any further work at sea until the autumn of last year (1927). In the interval, considerable modifications, which our previous experience had shown to be desirable, were made in the apparatus, and tests were carried out on the colour-sensitivity of the cells employed. Before giving details of the most recent marine measurements, a brief account will be given of the various modifications introduced and the laboratory tests which they involved.

For a detailed description of the apparatus reference must be made to the previous papers (1) and (2). The method consists in passing the current which flows through a photo-electric cell, under the influence of the light to be measured, through a known high resistance, and balancing the pressure drop across the latter against a potentiometer. A telephone is used as a detector, the current due to lack of balance being rendered intermittent by means of a special interrupter, and amplified by means of a 2-valve amplifier. By this means it is possible to measure currents down to about $10^{-9}$ ampere even when the steam trawler, on board which the work is done, is rolling heavily.

A general idea of the apparatus may be gained from Plate I, Figs. $A$ and $B$. $A$ shows the apparatus lying on the port side of the counter. The 
box projecting into the top left-hand corner contains the submarine photometer $(\mathrm{K})$ lying under its coiled cable ; lower down is seen a portion of the deck photometer $(\mathrm{G})$, mounted on gimbals; near this is submarine photometer $\mathrm{L}$, recognised by its thicker cables. The negative leads from all the photometers are attached to a 'bus bar on the positive terminal of the potentiometer in the large box, the positive terminals of the cables being plugged into the high-tension battery held in position by the bands and paraffin wax blocks seen on the left side of the large box. Note the arrangement of the strings for opening and closing the lid of L, also the loop attachment of the cable to avoid a sharp bend due to sagging. On the near left-hand corner of the large box is the rheostat for the valve filaments, next to it being the switch. Below these lies the $100,000 \mathrm{ohms}$ resistance. The front portion of the box is occupied by the potentiometer, under which lie the two dry cells for the valves, also the condenser used to increase the sensitivity. On the back wall of the box the amplifier may be seen, with telephones attached to the right-hand corner, next to which is the high-tension battery for the amplifying valves. Below this the standard cell is secured, but it is in the shade ; next it the potentiometer accumulator may be seen, and then the interrupter, showing vanes, counterpoise piece, winding key, and lever. For use, the box of apparatus was conveniently placed and lashed down on a shelf in the deck-house a few feet forward from the counter. In damp weather "dark currents" were minimised by opening a door communicating indirectly with the engine-room and by keeping a Primus stove, also lashed down, burning on the floor of the cabin.

The G photometer, mounted on gimbals, was placed on the deck-house roof, so as to be as clear as possible from all obstructions; the cables enter on the A azimuth of the photometer (see later). It was most convenient to turn this aft, so, as the ship's stern was always turned as nearly towards the sun as the wind allowed, the sunlight always fell within the $189^{\circ}$ of azimuth $\mathrm{D}, \mathrm{A}, \mathrm{B}$.

Figure $B$ shows one of the photometers being lowered, from a short pole lashed on to the boom, by a steel cable. The cables are being paid out amidships, the opening and closing strings being worked from starboard and port respectively. The raised centre bolt-head, seen more clearly in plate, $A$, acts as a stop when the closing string is pulled taut.

\section{Modifications in the Current-measuring Apparatus.}

The original interrupter proved to be rather delicate, and, as already mentioned, had to be kept at a distance from the rest of the apparatus, otherwise the current working the electric buzzer, which operated it, induced currents in the main circuits, and thus prevented the attainment 
PLATE I.

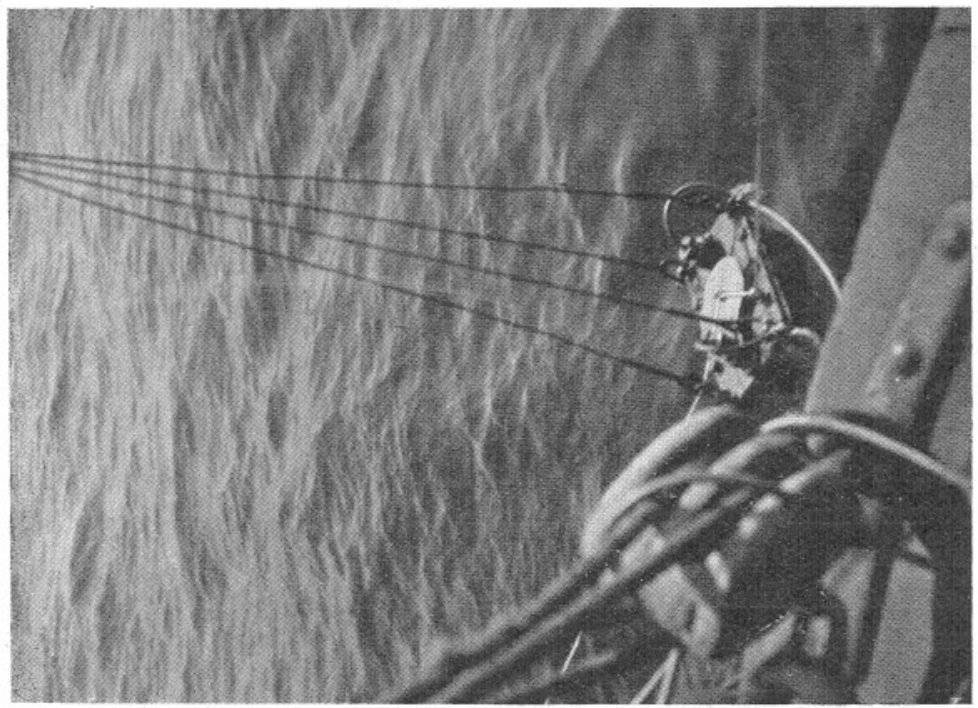

$\dot{9}$

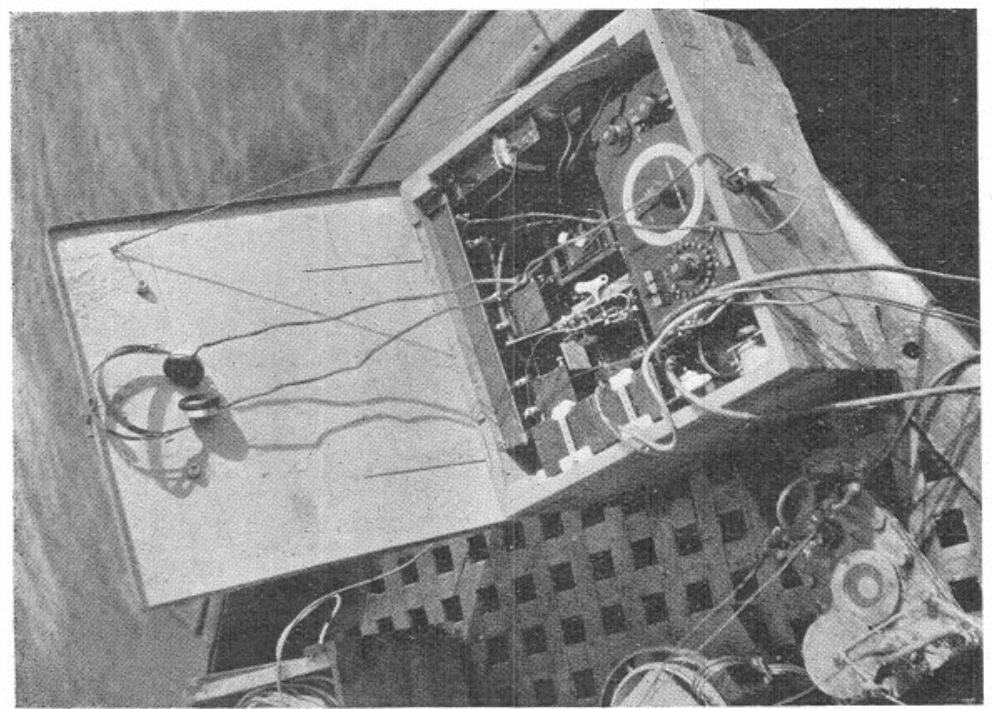


of a sharp balance. Similar effects upon the wires connecting the interrupter were occasioned by the electric lighting and power circuits in the laboratory, so that the apparatus was most conveniently used when all were switched off, or in a shed at Cawsand remote from external currents, or at sea. Accordingly, a new interrupter was made, which, being actuated by a clock spring, did not cause any induced currents, and, thus, could be mounted in the box with the rest of the apparatus. This eliminated the interference caused by electric light mains.

This interrupter is constructed almost entirely of Meccano parts, and consists of a spring motor driving a short train of gear wheels, the last spindle of which carries an aluminium air vane to reduce the speed of rotation to a suitable value. The same spindle carries a ratchet wheel, on which a smooth wheel rolls. The axle of the latter supports a light framework which is pivoted on an insulated fixed axle and counterpoised, so that there is only very light contact between the smooth and ratchet wheels. The current to be interrupted is led in to this insulated axle, and passes from that through the pivoted frame and the wheels to the main frame of the motor. As the smooth wheel only touches the tops of the teeth of the ratchet wheel and breaks contact in the intervening spaces, the circuit is broken once for every tooth. It is found best to arrange that the speed of rotation of the ratchet wheel is comparatively slow, say a few revolutions per second. The variation in speed, caused by the running down of the clock spring, does not appreciably affect the sensitivity. Winding, which is required about every five minutes, is facilitated by a ratchet gear.

The interrupter is mounted on rubber buffers and felt pads in the box containing the rest of the apparatus. The rubber insulates it from the box, and helps to deaden the noise made by the wheels. This is further assisted by the felt pads which are interposed between the rubber and the box.

As this interrupter does not cause any induced currents a rather sharper balance is attainable. This renders it advantageous to increase the resistance across which the potential difference is measured. Moreover, the resistance previously used had to be discarded, as its very fine wire broke somewhere inside the vitreous insulation, causing the resistance to become almost infinite. Accordingly, it was replaced by a wellinsulated bobbin-type variable resistance. This can be increased in steps of $10,000 \mathrm{ohms}$ from 0 to $100,000 \mathrm{ohms}$. For the small currents available with photo-electric cells it was always used at its maximum value. This makes one potentiometer scale division represent $10^{-9}$ ampere. Under favourable circumstances a measurement could be made to within about 0.5 scale division, or $5 \times 10^{-10}$ ampere. For these measurements the potentiometer was used on its lower range, namely, with the one-tenth multiplier plug in position. 


\section{Modifications in the OLd Photometers G and K.}

It was found that the matt varnish used for obtaining a diffusing surface on the photometer windows darkened with time. In addition, it caused a large loss of sensitivity even when new. Accordingly, it was discarded, and windows of glass, ground on the inner face, substituted on both the photometers. Unfortunately, the diffusing properties of ground glass are very poor, so that the effect of obliquity of illumination is quite different for such a photometer from that for a perfectly diffusing surface. Moreover, even if the photometer window is horizontal (the usual working position), the effect of illumination by a beam light of a given altitude generally varies considerably with the azimuth of the beam relative to the photometer. Thus it was necessary to calibrate the photometers for the effects of the altitude and the azimuth of the illumination, as described later.

The new window of the air photometer (denoted henceforth by the letter $\mathrm{G}$ ) is $12 \mathrm{~cm}$. in diameter. It is surrounded by thin sheet zinc, so that there is no appreciable screening of low angle light. The potassium vacuum photo-electric cell is mounted just below the centre of the window. As no diaphragm is introduced between the cell and this large window, it is possible that some light enters the cell through apertures in the metallic coating, in addition to what comes in through the actual pupil of the cell. This may account for some of the differences in sensitivity found for beams of the same altitude, but of different azimuths. This view is supported by the fact that, in the two submarine photometers, which have small windows, and are fitted with reflecting collars to direct all light entering the window into the pupil of the cell, the effect of azimuth is much less important. Moreover, when a thin sheet metal diaphragm of about $5 \mathrm{~cm}$. aperture was placed over the window of the air photometer, not only was the average effect of altitude changed, but, in addition, the relative sensitivities at different azimuths was entirely altered. It is accordingly proposed to try the effect of fitting a diaphragm tightly round the cell pupil, so as to prevent the entry of any light except through the pupil itself.

The sensitivity of the submarine photometer $(K)$ (which contains a gas-filled potassium-hydride cell of the Kunz type) to oblique light could not be increased by increasing the size of the window, in view of the pressure which it must bear. Some improvement in the oblique sensitivity was effected by the use of a cylindrical collar, of sheet aluminium, about $3 \mathrm{~cm}$. diameter by $0.75 \mathrm{~cm}$. deep, the surface being matted and coated with celluloid varnish. This fits closely round the rim of the pupil of the cell and fills up the space between this rim and the rim of the window in the gun-metal case. Thus, most of the oblique light which, 
if it passes through the marginal parts of the window, might otherwise not enter the cell, is reflected so as to do so.

The loss of light is much less in this ground-glass window than in the matt-varnished one previously employed ; the window is somewhat larger, the mirror reduces internal losses, and, finally, the sensitivity of the current-measuring apparatus is nearly twice as great, so the light sensitivity has been so much increased that it has been possible to extend the measurements to almost twice the depth. This has necessitated the fitting of connecting cables each about 90 metres long. In order to prevent these from being unduly heavy they have a lesser thickness of rubber insulation than those used previously, being only about $7 \mathrm{~mm}$., over-all diameter, instead of $11 \mathrm{~mm}$.

\section{New Vacuum Submarine Photometer L.}

As it was considered that more reliance could be placed on the results if they were not entirely dependent on the readings of a gas-filled cell, a new submarine photometer $(\mathrm{L})$ has been made. The case is similar to the old one. A modified form of shutter, which can be more readily opened and closed by two strings, has been fitted to both photometers.

A large vacuum cell, specially made by the General Electric Co., is fitted in this photometer in place of the Kunz cell. Apart from the difference-between the cells, the chief optical difference between the photometers lies in the fact that in $\mathrm{L}$ the reflecting collar is conical, and made of polished silver, widening from $2 \cdot 0 \mathrm{~cm}$. internal diameter, where it is in contact with the rim of the window, to $2.7 \mathrm{~cm}$. where it meets the rim of the pupil of the cell. This conical mirror is more effective than the cylindrical one in increasing the relative sensitivity to oblique light. The reduction of the effective aperture from $3 \mathrm{~cm}$. to $2 \mathrm{~cm}$. reduces the sensitivity to direct light; but, for the diffuse light occurring in the sea, the reduction caused by the mirror is small. This $\mathrm{L}$ photometer is fitted with the $11 \mathrm{~mm}$. cables, which had previously been used on the $\mathrm{K}$ photometer. The length (45 metres) of these cables is, perhaps, sufficient, as, owing to the relative insensitiveness of the vacuum cell, this photometer can only be used at lesser depths than can the $\mathrm{K}$ photometer. It has, however, been used down to 40 metres, which is 5 metres deeper than the greatest depth at which the K photometer was worked in 1925. The latter has now been used down to 65 metres.

\section{Standardisation of Photometers.}

As before, an open carbon arc lamp was used for standardising the vacuum photometers, but the process has been simplified by making use of the work of Forrest (4) and Allen (5). The former has shown that 
the luminosity perpendicular to the face of the positive carbon is about 173 candle-power per square $\mathrm{mm}$., and the latter found that under the conditions of his work the current was 0.746 ampere per square $\mathrm{mm}$. Combining these two we get 232 c.p. per ampere in a direction perpendicular to the face of the positive carbon.

The carbons ( $7 \mathrm{~mm}$. solid) were vertical, the positive being above, and a magnified image of the arc was thrown on a screen by means of a lens. This enabled us to ensure $(a)$ that the end of the positive carbon was maintained in the same position, $(b)$ that the end was very nearly horizontal, and $(c)$ that the arc was sufficiently long to ensure that, at an angle of $45^{\circ}$ to the vertical, no part of the positive carbon was blocked out by the negative one. The photometer to be tested was fixed at a measured distance (15 to $20 \mathrm{~cm}$.) from the positive crater, the line joining the crater and the centre of the pupil making an angle of $45^{\circ}$ with the vertical and being perpendicular to the window of the photometer. The candle-power of the arc along this line was obviously $0 \cdot 707 \times 232$ times the current in amperes. Thus, by measuring this current with a good ammeter, when the conditions were steady, the illumination on the photometer was found. About eight to ten readings of the photo-electric current were taken, the extreme readings deviating about $5 \%$ from the mean.

In this way it was found that a current of $10^{-9}$ ampere through the air photometer G represented an illumination of 69.5 metre candles. The same current through the new submarine photometer $\mathrm{L}$ corresponded to 17.8 metre candles. There was obviously no use in standardising the old submarine photometer in this way, as its sensitivity varies from day to day. Both of these standardisations were made with an anode potential of 60 volts. Tests of the effect of anode potential on the sensitivity of $\mathrm{G}$ showed that for voltages between 60 and 120 the sensitivity increased about $0.39 \%$ of its value at 60 , per volt. For $\mathrm{L}$ the corresponding figure was $0.36 \%$, the characteristics of the two photometers being very similar over a range of voltages 12 to 120 .

In the previous standardisations the line of illumination made an angle of $63^{\circ}$ with the axis of the carbons, the current being 10 amperes. This should, on the above assumptions, have given a candle-power of 1053, if the face of the carbon was at right angles to its axis. The candlepower actually measured was 1250 on one occasion and 953 on another. The variation may have been partly due to slight obliquity of the carbon face, and partly to differences in the positive carbons, which in these earlier measurements were $12 \mathrm{~mm}$., cored. The general agreement between the two methods of finding the candle-power of the arc is, however, quite satisfactory. Tests of $\mathrm{G}$ by this method, with the old matt-varnished window darkened with age, showed a sensitivity of $10^{-9}$ amp. per 200 
metre candles. The sensitivity found by the old method, when the window was new, was 150 m.c.

\section{Test Lantern for Detecting possible Changes in Sensitivity.}

Although there is no evidence of any change in the sensitivity of the $G$ cell in the course of some years, a test lantern has been constructed as a check on possible changes.

It consists of a large white enamelled iron tumbler, through the bottom of which a circular hole is bored large enough to take a small lampholder which carries a 6 -volt, 18 -watt vacuum lamp. The flexible leads are soldered to the lamp contacts, so as to eliminate the possibility of errors due to variations in the resistance of the lamp-holder contacts. When this lantern is placed standing on its rim centrally on the photometer window the lamp is at a fixed distance from the cell. The voltage applied to the ends of the lamp leads was varied from $5 \cdot 0$ to $5 \cdot 6$, and the corresponding relative changes of illumination measured by the $\mathrm{L}$ photometer. In this way it was found that small variations of voltage in the immediate neighbourhood of $5 \cdot 50$, which was taken as the standard, caused a change of illumination of $80 \%$ per volt.

The lantern was standardised for each photometer shortly after the latter had been standardised with the arc, and the illumination in metre candles recorded. This illumination will generally differ for different photometers. Thus with $\mathrm{G}$, the test lantern gave an illumination of 3000 m.c., while with L it only gave 2100 m.c. This difference is to be ascribed to the facts that $(a)$ with $\mathrm{L}$ the lantern stands on the brass rim and not directly on the window, and the window itself is thicker, so that the lamp is over a centimetre further from the cell, $(b) \mathrm{L}$ is relatively less sensitive to the oblique light reflected from the white enamel, and (c) $\mathrm{L}$ is relatively less sensitive to yellow and green light than $\mathrm{G}$.

As this lamp is only used occasionally for a few minutes, and at a reduced voltage, its candle-power should remain approximately constant for years. Tests of photometer G made in Dublin and Plymouth, respectively, with an interval of nearly five months, gave almost exactly the same sensivity.

\section{Effect of Obliquity of Illumination.}

A 12-volt, 48-watt gas-filled lamp (head-lamp type) was mounted on a circular brass scale, divided in degrees, so that the filament of the lamp could be placed anywhere on a vertical semicircle $14.5 \mathrm{~cm}$. radius, at the centre of which the pupil of the photometer was placed with the window 
horizontal. In this way the effect of obliquity was found for four rectangular azimuths for each photometer. The results are plotted in Fig. 1, which shows the relative effect of a beam of parallel light of variable altitude for four rectangular azimuths A, B, C, and D with photometer $\mathrm{G}$, and the mean effects for $\mathrm{K}$ and $\mathrm{L}$. In the latter cases the differences between the various azimuths were very much smaller than with $\mathrm{G}$.

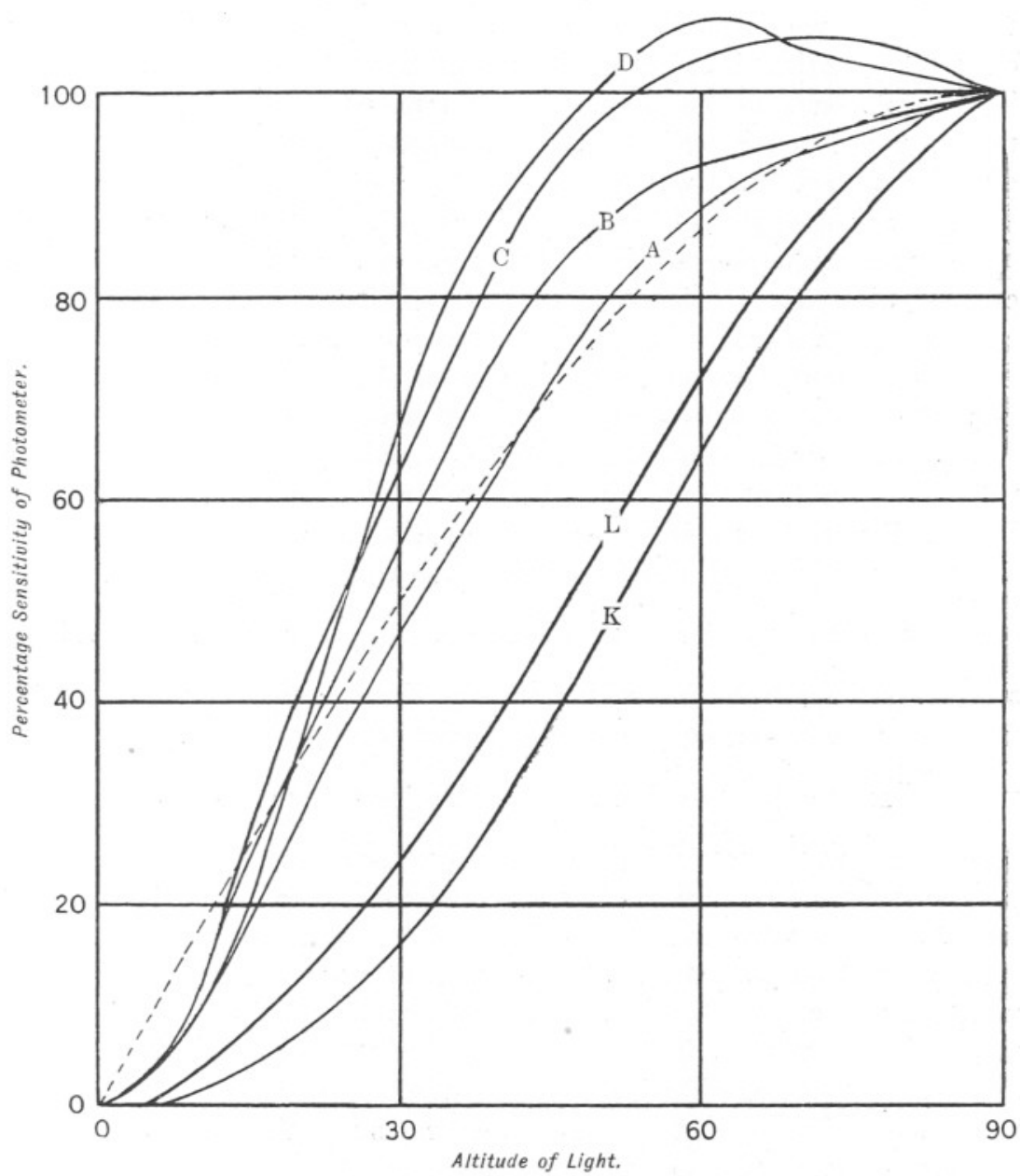

FIG. 1.-The ordinates are percentage sensitivities of the photometers and the abscissæ the altitude of the light source in degrees. Curves A, B, C, and D show the relative effects of a beam of parallel light of variable altitude for four rectangular azimuths on photometer G. Curves $\mathrm{K}$ and $\mathrm{L}$ show the mean effects for each of the four azimuths for these photometers, the differences between the various azimuths were very much smaller than with $G$. The dotted sine curve shows what the effect would be with a perfect diffusing surface and no reflection losses at the front surface of the window. 
The dotted sine curve shows what the effect would be if the diffusing surface were perfect, and reflection losses at the front surface of the window absent. It will be observed that $\mathrm{K}$ and $\mathrm{L}$ are both very insensitive to oblique light. G, except at very low altitudes, is, for most azimuths, more sensitive to oblique light than it would be if the diffusing properties of the window were perfect. The ratio of the sine of the altitude to the ordinate of the given obliquity curve at that altitude gives the factor by which the reading of the photometer must be multiplied to obtain the vertical illumination $\mathrm{V}_{\mathrm{a}}$ when the photometer is used in air. This corresponds to the factor $f(\boldsymbol{2}$, p. 184), which effected the correction for the reflection loss, since in these earlier experiments the diffusing surface itself was almost perfect. The value of the obliquity factor for diffuse light is found, as before, by dividing the sky into 9 zones.

The water photometers $\mathrm{K}$ and $\mathrm{L}$ were tested with their windows covered with water. This is their usual condition when they are being calibrated at sea. This thin layer of water increases the sensitivity by $1.7 \%$ for vertical light and rather more for oblique light, but the effect is small compared with other sources of error, so that its presence or absence is of little importance. When a photometer is in use under water it is the light in the water that we are interested in, but when it is being calibrated above water by comparison with the $\mathrm{G}$ photometer it is the light in the air that is the same for both, the light in the water covering the photometer window being less in the ratio $\frac{V_{w}}{V_{a}}(2, p .184)$ since the surface of this layer is unruffled. Thus to obtain the submarine vertical illumination we must multiply the submerged reading by the value of $\frac{V_{\mathrm{w}}}{\mathrm{V}_{\mathrm{a}}}$ for the given conditions. The most convenient method is to combine this factor with the obliquity factor, so that for a given photometer we have different obliquity factors according as the photometer is used in air or in water.

As will be seen later, there is good reason to think that, except, possibly, within a few metres of the surface, the average obliquity of the submarine illumination is almost independent of that in the air above. It apparently does not differ greatly from the value found by calculation for a smooth water surface and a uniform sky. Thus all submarine readings of either photometer have been multiplied by the obliquity factor of that photometer, for these conditions.

\section{Colour-Sensitivity of the Photometers.}

A simple form of spectrum projector was constructed as follows. A Pointolite lamp, run off an 84-volt storage battery, was mounted on the 
carriage of an old vernier microscope, so that it could be moved at right angles to the axis of a Grubb portrait lens of about $22 \mathrm{~cm}$. focus and $6 \mathrm{~cm}$. aperture. Behind this was a $60^{\circ}$ carbon disulphide prism of $6 \mathrm{~cm}$. edge, forming a rather impure, but very bright, spectrum at a distance of nearly a metre behind the lens. This was thrown on a very wide "slit" about $5.5 \mathrm{~mm}$. wide, behind which the photometer could be placed. Thus, by screwing the carrier holding the lamp along its scale the band of the spectrum entering the cell could be changed. Special precautions were taken to reduce stray light as much as possible. The apparatus was standardised by covering the " slit" with tissue paper and observing the diffused, emergent light with a direct vision spectroscope. This enabled the mean wave length, and the total width of the spectrum band corresponding to any given setting of the lamp, to be found. This width varied from about $500 \AA$ A.U. for the red end of the spectrum to 300 in the green and 200 in the blue-violet.

The energy in this band was measured with a Moll vacuum thermopile and a very sensitive Kipp und Zonen Type Z galvanometer. Although the low resistance of this galvanometer renders it more suitable for thermo-electric than for photo-electric work, it.was found to be quite sensitive enough to measure the photo-electric currents flowing in this test. Accordingly, it was used for both thermopile and photometers, and the ratio of the photo-electric to the thermo-electric current, for any given lamp setting, was taken as the relative sensitivity of the cell for light of the wave length corresponding to the centre of the spectrum band used.

The curves obtained for the three photometers, and also for three other photometers, $\mathrm{H}, \mathrm{N}$, and $\mathrm{C}$, used in light measurements on shore, are shown in Fig. 2. H contains a vacuum potassium cell, similar to $G$, but somewhat larger and considerably more sensitive. $\mathrm{N}$ contains a vacuum sodium cell, and C a gas-filled cæsium cell.* The impurity of the spectrum probably has the effect of rendering the values given for the sensitivity near the red end of the range somewhat too high. It is hoped to modify the arrangement so as to increase considerably the purity of the spectrum, without rendering the quantity of energy transmitted towards the blue end of the spectrum too small for accurate measurement.

The results show good general agreement with those of other workers. The three photometers, G, H, and L, employ potassium as an active element. Even these show appreciable differences in colour sensitivity. $\mathrm{K}$ contains a Kunz gas-filled cell, and, we believe, has a potassium hydride kathode. This, as is known, is relatively more sensitive to green light than cells with pure potassium kathodes. The slight difference between the colour sensitivities of $\mathrm{K}$ and $\mathrm{L}$ should be remembered when considering the results obtained with them under water. Its effect

\footnotetext{
* Obtained from the Cambridge Sci. Inst. Co.
} 
was apparently small, as the absorption coefficients obtained with the two photometers generally agreed closely.

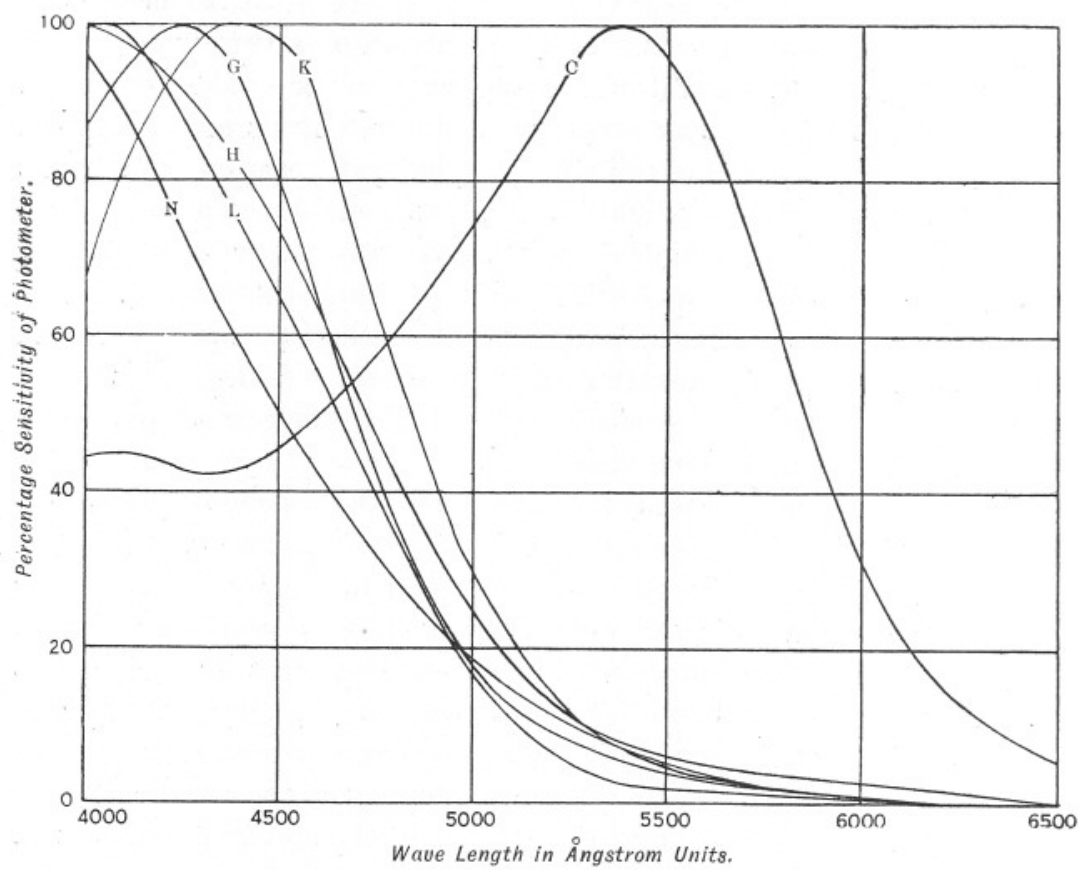

Frg. 2,-The ordinates show the percentage sensitivity of the photometers for various wave lengths as plotted in Angstrom units on the abscissæ. The photometers contain photo-electric cells as follows : C, a gas-filled cæsium cell ; K, a gas-filled potassium-hydride cell ; G, H, and $\mathrm{L}$, vacuum potassium cells; N, a vacuum sodium cell.

\section{Submarine Measurements, 1927.}

The greatly increased sensitivity of $\mathrm{K}$ rendered it expedient to reduce further the anode potential when making the above-water calibrations at the commenoement and end of each series.

In the first 1927 measurements 12 volts was used. As this gave a very large current $\left(5 \times 10^{-6} \mathrm{amp}\right.$.) with strong sunlight, it was subsequently reduced to 7 and, later, to 3 volts. The latter voltage is quite sufficient, as it generally renders $\mathrm{K}$ more sensitive than $\mathrm{G}$, and will be used in future.

The anode potential of the standard photometer $G$ was always about 67 volts, small corrections being made for the effect of small voltage changes on the sensitivity. L, which was not used as a standard, can safely be used in any light with anode potentials up to at least 120 volts, but the increase in sensitivity caused by raising the voltage above 60 is small, and it was generally used with a potential of $60-70$ volts. 
In the open sea it is only under exceptional circumstances that the light within a few metres of the surface is steady enough to be measured by our method. Accordingly, the usual procedure during 1927 was to make the shallowest submarine set of readings at 5 metres below the surface, and further sets at intervals of 5 metres down to the limit imposed either by the depth of the water or by the sensitivity of the photometer.

For comparatively shallow readings and bright surface light $\mathrm{L}$ is superior to $\mathrm{K}$, owing to its freedom from the troublesome changes of sensitivity to which the latter is liable. It is, however, not suitable for measuring illuminations much below 100 m.c., so for the deeper readings $\mathrm{K}$ must be used.

When using $\mathrm{K}$ the anode potential needed to be raised, at a depth of 15 or 20 metres, in order to increase its sensitivity. The voltage used for these intermediate depths was usually either 39 or 67 , these sockets in the high tension batteries being conveniently placed for plugging in the wander plug attached to the positive lead. A comparison of the readings with the different potentials enabled the voltage factor, correcting for increase in sensitivity, to be ascertained. At a depth of 25 to 40 metres the sensitivity was further increased by raising the anode potential to 120 volts. Time seldom permitted of a complete series of ascending readings after the greatest depth had been attained; but sets of readings, at both anode potentials, were taken at those levels at which the voltage had been changed on the descent.

Further determinations were thus made of the voltage factors. The ascending and descending factors generally differed slightly, and the mean was used. The series terminated with a calibration reading. This, with $\mathrm{K}$, might show a variation of sensitivity as high as $30 \%$ during the series. The sensitivity was assumed to have changed uniformly with time during the series, and a suitable correction applied to each set of readings. "Dark currents" were rather more troublesome than before. This was partly due to the increased sensitivity of the apparatus and the smallness of the photo-electric currents at the greater depths now attained. The fact that the insulation of the cables of the $\mathrm{K}$ photometer is much thinner than formerly probably explains the occurrence of appreciable "soakage" currents, which were now observed for the first time. These become of importance when the anode potential is large and the true photo-electric current small. Under these conditions the values found during the first couple of minutes after connecting the anode potential are appreciably larger than those obtained subsequently. These sources of error were eliminated by keeping the anode potential on continuously and taking alternate readings with the photometer shutter open and closed. Readings of $\mathrm{G}$ may be taken with the shutter of $\mathrm{K}$ closed, without cutting off the anode potential from the latter. 


\section{Calculation of Illumination from Photometer Readings.}

It may be as well to collect the various factors, already mentioned, by which the photo-electric currents must be multiplied in order to obtain the vertical illumination. In the case of the standard photometer G, we must multiply by the obliquity factor, as estimated for the given altitude of the sun, its azimuth relative to the photometer, and the relative proportions of sunlight and diffuse light. This factor generally does not differ much from unity.

The vertical illumination in metre candles is then found by multiplying the result so obtained by the number of metre candles corresponding to $10^{-9}$ ampere for the given value of the anode potential.

In general $\mathrm{L}$ was not used as a standard, as its sensitivity had not been checked with the testing lantern since it was standardised some months before, and its relative insensitivity to oblique light, as compared with the perpendicular illumination used in standardisation, rendered it somewhat unsuitable for the direct measurement of daylight. The ratio of its reading at any depth multiplied by the diffuse obliquity factor for water, to its reading in air multiplied by the air obliquity factor for the given conditions, gives the ratio of the submarine vertical illumination. at that depth to the surface vertical illumination, which is found from the simultaneous reading of $\mathrm{G}$.

The readings of $\mathrm{K}$ are treated in the same way, except that, in addition: to the obliquity factor, the submarine reading may require to be multiplied by an anode voltage factor, to allow for increase in sensitivity caused by increase of anode potential, and by a time factor, to compensate for the variation of sensitivity with time.

As an example of the method of calculation we give the figures for Series 22. On this occasion all three photometers were in use, as the weather was so bad that photometer $\mathrm{L}$ was used on deck as a substandard instead of G, which was only used at the conclusion of the series for standardising $\mathrm{L}$.

Taking this standardisation first, the anode potential for photometer $\mathrm{G}$ was $112 \cdot 0$ volts, which corresponds to a sensitivity of $57 \cdot 6$ metre candles. per $10^{-9}$ ampere. The standardisation was made at 3.45 p.m., at which time the altitude of the sun $(\alpha)$ was $4^{\circ}$. The conditions were such that the direct sunlight was negligible compared with the diffuse light, i.e. $\beta=1$, where $\beta$ is the ratio of the total vertical illumination to the illumination with the direct sunlight screened off. Hence the obliquity factor for $G\left(f_{g}\right)$ was that for diffuse light, which had been calculated to be $0 \cdot 915$. If sunlight had been present it would have been necessary to interpolate between this diffuse value of $f_{g}$ and the value for pure sunlight of the proper altitude and relative azimuth (2, p. 183). The means. 
of several alternate readings of photometers $\mathrm{G}$ and $\mathrm{L}$ were $98 \times 10^{-9}$ ampere for each photometer. Hence the vertical illumination was $98 \times 0 \cdot 915 \times 57 \cdot 6=5 \cdot 16 \times 10^{3}$ metre candles.

Now the value of the $L$ obliquity factor $f_{1}$ for diffuse light in air is $1 \cdot 56$, so the corrected reading of $\mathrm{L}$ becomes $98 \times 1 \cdot 56=153$. Dividing this into 5160 we find that for $\mathrm{L}$ one scale unit $\left[10^{-9}\right.$ ampere $]$ of the corrected reading corresponded to $33 \cdot 7$ metre candles. The anode potential used with $\mathrm{L}$ was, on this occasion, only $10 \cdot 6$ volts. The sensitivity deduced for this voltage from the laboratory tests done 8 months before is about 32.5 metre candles, so the agreement is quite satisfactory.

\section{TABLE I.}

Measurements at International Hydrographical Station E1, on December 14, 1927.

\begin{tabular}{|c|c|c|c|c|c|c|c|c|c|c|c|c|}
\hline $\mathrm{T}$ & & $\alpha$ & B & d & L & $\mathrm{K}_{3}$ & $\mathrm{~K}_{43}$ & $f_{1}$ & $f_{k}$ & $\mathrm{t}$ & $V_{\mathrm{a}}$ & V \\
\hline $.5 \mathrm{p}$. & m. & $15^{\circ}$ & 1.5 & $\mathrm{~g}$ & 482 & 536 & - & $1 \cdot 89$ & $2 \cdot 31$ & $1 \cdot 08$ & $30 \cdot 8$ & $30 \cdot 8$ \\
\hline 30 & , & 14 & 1 & 5 & 280 & 162 & - & 1.56 & $1 \cdot 60$ & $1 \cdot 07$ & $14 \cdot 7$ & $6 \cdot 4$ \\
\hline .52 & ", & 13 & , & 10 & 321 & 102 & - & , & , , & $1 \cdot 06$ & $16 \cdot 9$ & $4 \cdot 0$ \\
\hline 0 & " &, &, & 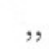 & - & 126 & 630 & , & & " & - & $4 \cdot 9$ \\
\hline 8 & , & 12 & ," & 20 & 232 & $(26 \cdot 2)$ & 131 & 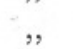 & & 1.05 & $12 \cdot 2$ & 1.01 \\
\hline .29 & , & 10 & , & 30 & 266 & $(12 \cdot 0)$ & 60 & $"$ & & $1 \cdot 04$ & $14 \cdot 0$ & $0 \cdot 46$ \\
\hline 44 & , & 9 & , & 35 & 233 & $(8 \cdot 4)$ & 42 & , & , & $1 \cdot 03$ & $12 \cdot 25$ & $0 \cdot 32$ \\
\hline 58 & , & 8 & , & 20 & 226 & $(29 \cdot 0)$ & 145 & , & 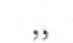 & $1 \cdot 02$ & $11 \cdot 9$ & $1 \cdot 09$ \\
\hline 10 & , & 7 & , & 10 & 185 & $(77)$ & 385 & , & , & $1 \cdot 01$ & $9 \cdot 75$ & $2 \cdot 86$ \\
\hline 16 & , & 6 & , & ", & - & 75 & 372 & , & & 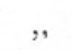 & - & 2.78 \\
\hline 30 & " & 5 & , & $\mathrm{g}$ & 134 & 180 & - & , & $1 \cdot 71$ & $1 \cdot 00$ & $7 \cdot 05$ & $7 \cdot 05$ \\
\hline
\end{tabular}

The remainder of the readings constituting Series 22 are shown in Table I. Here $\mathrm{T}$ is the clock time (G.M.T.) and $\mathrm{d}$ the depth in metres of photometer $\mathrm{K}$, the letter $\mathrm{g}$ in this column denoting that it was on the raised stern grating beside the substandard $\mathrm{L}$, whose readings are shown under column $\mathrm{L}$. The columns $\mathrm{K}_{3}$ and $\mathrm{K}_{43}$ show the mean readings of $\mathrm{K}$ with anode voltages 3 and 43 (nominal), respectively. It will be noticed that readings at both voltages were made at a depth of 10 metres, both on the descent and on the ascent. The two values found for $\frac{\mathrm{K}_{3}}{\mathrm{~K}_{43}}$ were $0 \cdot 200$ and $0 \cdot 201$, respectively. The agreement was seldom, however, as good as this, and the usual practice is to take the mean of the descending and ascending values. In this way we get the voltage factor- $0 \cdot 200$ in this case - by which the deeper readings must be multiplied to correct for the increased sensitivity caused by the increase in 
anode potential. The reduced values obtained in this way are entered in brackets in the $K_{3}$ column. For very weak illuminations a further increase in anode voltage up to about 120 would be necessary, the voltage factor being found by comparison of the readings with high and intermediate voltages, respectively. The voltage factor found at 120 volts in another series was $0 \cdot 029$, i.e. raising the potential had multiplied the sensitivity of the photometer by 34 .

The obliquity factors for $L$ and $K$ are given under $f_{l}$ and $f_{k}$. During the first set of readings there was appreciable sunlight, $\beta$ being estimated at about 1.5. Later, owing to clouds and the declining altitude of the sun, $\beta$ became sensibly equal to unity. Accordingly the first values of $f_{l}$ and $f_{k}$ differ from all the others. The first and the last values of $f_{k}$ are the air factors, the other entries being the value of the diffuse light water factor. The vertical illumination in air, $\mathrm{V}_{\mathrm{a}}$, is equal to $33 \cdot 7 \times$ $\mathrm{f}_{1} \times \mathrm{L}$. The unit adopted in the table is 1000 metre candles.

The initial value of the product $\mathrm{f}_{\mathrm{k}} \mathrm{K}_{3}$ is $1240, \mathrm{~V}_{\mathrm{a}}$ being $30 \cdot 8 \times 10^{3}$ m.c., this corresponds to an initial sensitivity for $K_{3}$ of $24 \cdot 8$ m.c. per unit. The corresponding figures obtained at the conclusion of the series are 308 units, $7 \cdot 05 \times 10^{3}$ m.c., and $22 \cdot 9$ m.c. per unit. This apparent increase of sensitivity in $\mathrm{K}$ by about $8 \%$ may be partly due to differences between the actual light distribution and the ideal distributions for which the obliquity factors were calculated, or to the slight difference in coloursensitivity of the two photometers, $\mathrm{K}$ being relatively more sensitive to the longer wave lengths. As, however, a change of sensitivity of $\mathrm{K}$, amounting occasionally to over $30 \%$, commonly occurs during a series, the usual practice is here followed of assuming that the sensitivity changes uniformly with the time, and introducing a time factor $t$, which makes the two calibrations agree. The product $22.9 \times \mathrm{tf}_{\mathrm{k}} \mathrm{K}$ then gives the vertical illumination $\mathrm{V}$ recorded by photometer $\mathrm{K}$, the first and last values, of course, being identical with those for $V_{a}$.

The vertical absorption coefficient $\lambda$ measures the relative reduction of illumination per metre. It is defined by the well-known equation, $\mathrm{V}=\mathrm{V}_{\mathrm{o}} \mathrm{e}^{-\lambda d}$. If $\mathrm{V}_{1}$ and $\mathrm{V}_{2}$ are simultaneous values of $\mathrm{V}$ at two points differing in depth by $\delta$ metres, evidently $\lambda=\frac{2 \cdot 3}{\delta}\left(\log _{10} V_{1}-\log _{10} V_{2}\right)$. Since, however, we do not measure $V_{1}$ and $V_{2}$ simultaneously, we must allow for variations in the surface light. The most convenient way of doing so is to record the illumination at any depth as a percentage $p$ of the simultaneous value of the surface light $\mathrm{V}_{\mathrm{a}}$. Then $\lambda=\frac{2 \cdot 3}{\delta}\left(\log _{10} \mathrm{p}_{1}-\right.$ $\left.\log _{10} \mathrm{p}_{2}\right)$.

Values of $\mathrm{p}$ and $\lambda$ are given in Table 2 . 


\section{The Results.}

The results of the 1927 measurements are given in Table II, the serial numbers being consecutive with those in the last paper. $\lambda$, the vertical absorption coefficient of the water, is obtained from the ratio of the values of $\mathrm{p}$ for the two depths immediately above and below the given one. In a few cases the mean of these two depths differs somewhat from the depth opposite to which $\lambda$ is entered. An asterisk in this column indicates that the upper reading used in finding $\lambda$ is the above-water reading, a surface loss of $15 \%$ being assumed. The letter a in the depth column indicates that the photometer was slung just above the water. This was not practicable except in fairly smooth water, as the photometer swayed violently with the rolling of the ship. Under rough conditions the photometer was placed on the fender at the extremity of the counter, on the broad rail of the bulwarks, or on the grating inside the bulwarks. These positions, which are indicated by the letters $\mathrm{f}, \mathrm{r}$, and $\mathrm{g}$, respectively, involve less shading by the ship than position a. The effect of this shading is seen in Series 13, where raising the photometer a metre above the surface increased the reading by $20 \%$. The shading effect must also affect the submarine readings by varying amounts, but the errors so introduced are small compared with the large variations in illumination which occur.

If the photometer were suspended from a long spar so as to reduce the shading effect, larger errors would be caused by its greater vertical motion, which would also impose excessive strains on the gear. For the same reason it was found to be absolutely necessary to suspend the photometer on the centre line of the ship, so as to eliminate the effect of rolling.

It will be noticed that the illuminations recorded at a few levels with an ascending photometer usually exceeded those found at the same depth during the previous descending series. The discrepancy is only serious in Series 16, where it is so large as to suggest that an error may have been made in the depth. The cable was marked off in 5-metre lengths, and it is possible that a miscount may have occurred in hauling up, which would explain most of the discrepancy. In other cases the increase can only be explained by assuming that the ship was drifting into clearer water, or that there was a general tendency for the water to clear as the day advanced. In either case the deeper readings would be increased relative to the earlier shallow ones causing an apparent decrease of $\lambda$ with depth. The effect is generally small, and sometimes absent, or reversed; but it is worth noting, since it may explain some part of the difference between the 1927 and the 1925 results. The latter were mostly obtained in ascending order, so that the effect of progressive 


\section{TABLE II.}

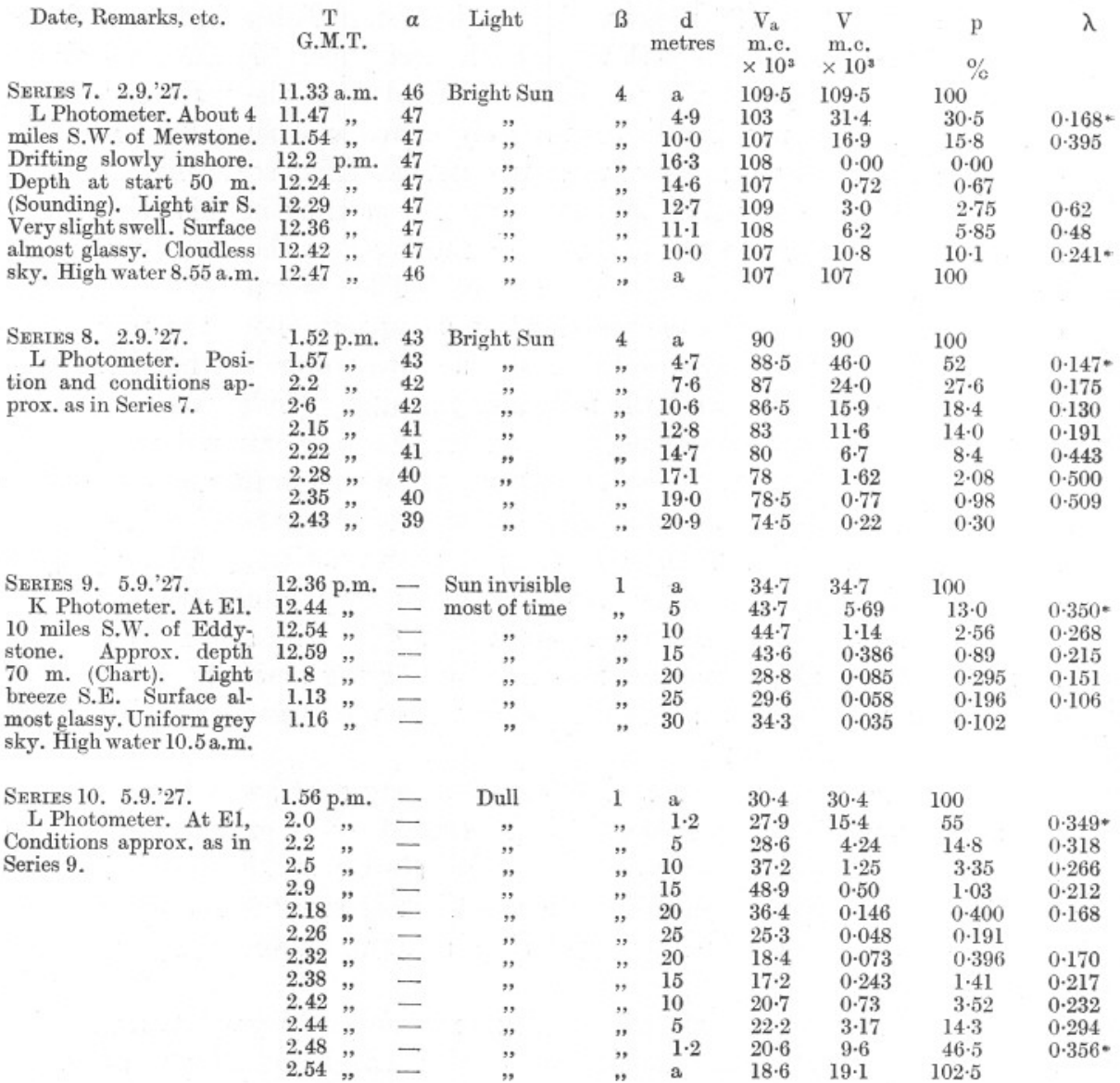

\begin{tabular}{|c|c|c|c|c|c|c|c|c|c|c|}
\hline SERIES 11. 7.9.'27. & 1.18 & p.m. & 44 & Bright Sun & 4 & a & 92 & 92 & 100 & \\
\hline K Photometer. At E1. & 1.22 & ," & 44 & 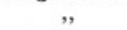 & $"$ & $1 \cdot 2$ & $93 \cdot 5$ & $54 \cdot 5$ & $58 \cdot 5$ & $0 \cdot 318$ \\
\hline Light breeze $W$. Blue & 1.26 & , & 44 & ," & ", & 5 & 100 & $17 \cdot 3$ & $17 \cdot 3$ & $0 \cdot 308$ * \\
\hline sky with light clouds. & 1.28 & ", & 44 & , & ," & 10 & $94 \cdot 5$ & $3 \cdot 69$ & $3 \cdot 90$ & $0 \cdot 295$ \\
\hline High water 1.34 p.m. & 1.32 & , & 43 & $"$ & , & 15 & $93 \cdot 5$ & 0.865 & $0 \cdot 925$ & $0 \cdot 267$ \\
\hline Secchi disc, $8 \mathrm{~m}$. at 12.15 & 1.38 & , & 43 & $"$ & $"$ & 20 & $99 \cdot 5$ & $0 \cdot 271$ & $0 \cdot 272$ & $0 \cdot 206$ \\
\hline p.m. & 1.45 & , & 42 & ," & ," & 25 & 90 & $0 \cdot 106$ & $0 \cdot 117$ & $0 \cdot 179$ \\
\hline & 1.52 & ", & 42 & ” & ", & 30 & $89 \cdot 5$ & 0.0405 & 0.045 & $0 \cdot 148$ \\
\hline & 1.56 & ", & 41 & $"$ & $"$ & 35 & $85 \cdot 5$ & $0 \cdot 023$ & $0 \cdot 027$ & $0 \cdot 128$ \\
\hline & 2.5 & ," & 40 & ", & ” & 40 & $83 \cdot 5$ & $0 \cdot 0105$ & 0.0125 & $0 \cdot 128$ \\
\hline & 2.12 & " & 39 & , & $"$ & 45 & 83 & 0.006 & 0.0075 & $0 \cdot 082$ \\
\hline & 2.16 & $"$ & 39 & $"$ & 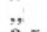 & 50 & 80 & $0 \cdot 0045$ & 0.0055 & 0.051 \\
\hline & 2.23 & , & 38 & , & $3 \cdot 5$ & 55 & 79 & $0 \cdot 0035$ & 0.0045 & 0.061 \\
\hline & 2.28 & ", & 38 & " & ", & 60 & 79 & 0.0025 & $0 \cdot 003$ & \\
\hline & 2.38 & ", & 37 & ", & , & 35 & $76 \cdot 5$ & 0.0275 & 0.036 & \\
\hline & 2.46 & " & 36 & " & ," & 25 & $75 \cdot 5$ & $0 \cdot 182$ & $0 \cdot 231$ & \\
\hline & $2 \cdot 53$ & ", & 35 & , & ", & 15 & 78 & $1 \cdot 15$ & 1.47 & \\
\hline & 3.1 & , & 34 & , & ," & f & 74 & 74 & 100 & \\
\hline
\end{tabular}




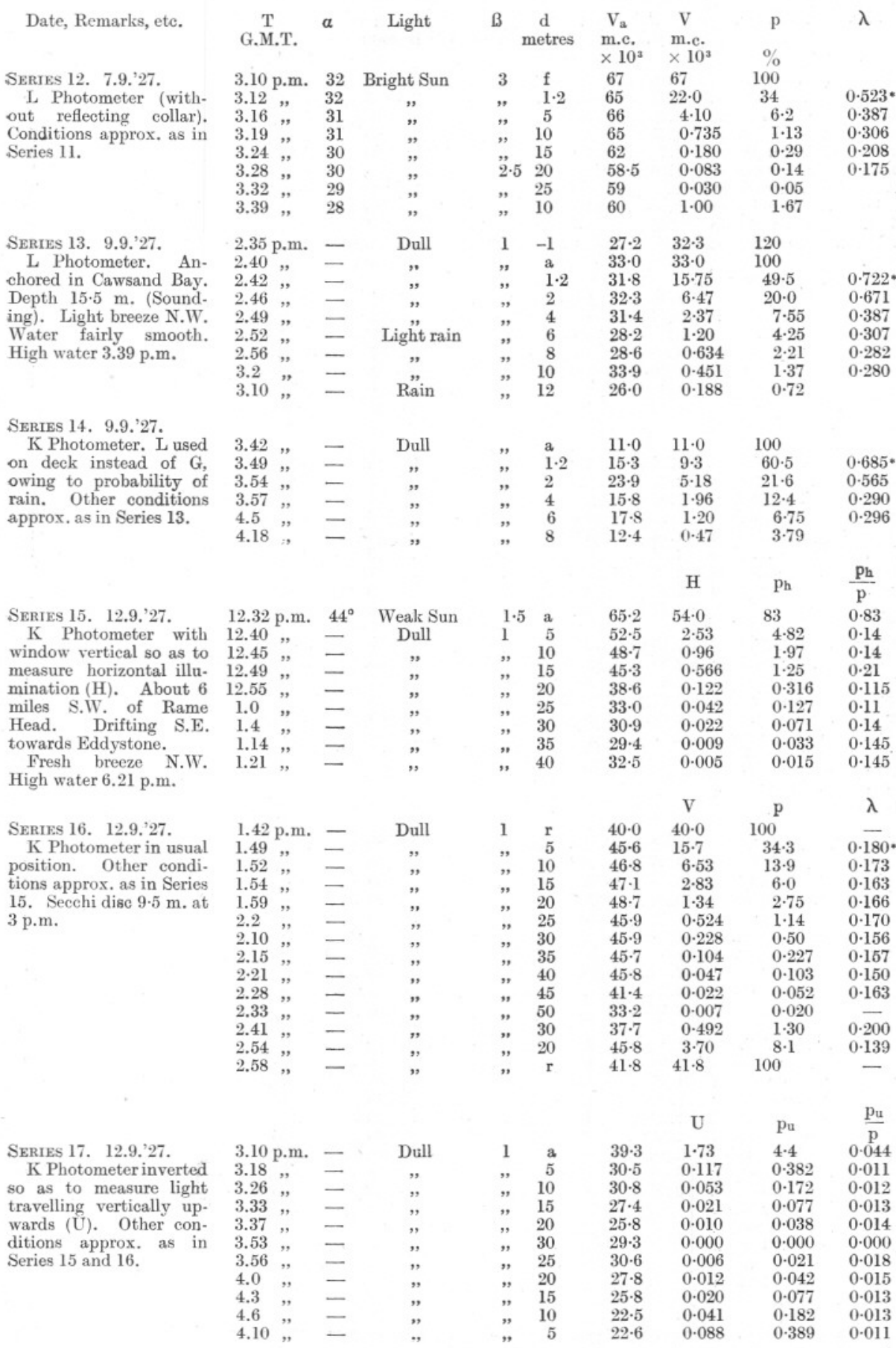




Date, Remarks, etc.
SErmes 18. 3.10.'27.
K Photometer at El.
Light breeze N.E. Long
swell from S.W. Clear
sky. Depth $73 \mathrm{~m}$. Water
column almost isother-
mal, $\mathrm{t}=13 \cdot 8^{\circ}$. High water
9.26 a.m. Secchi disc
$15 \mathrm{~m}$. in shadow of ship
at 5 p.m. Disc appeared
green.

Interval. Cloud over sun.
SERIES 19. 5.10.'27.

L Photometer. About

1 mile N.W. of Eddy-

stone. Drifting slowly

inshore. Depth at start

$57 \mathrm{~m}$. (Sounding). Light

breeze N.E. Considerable

swell. High water 11.39

a.m.

Series 20. 5.10.'27.

L Photometer used for first three sets of read. ings. $\mathrm{K}$ Photometer used for last three sets. assumed to be the same for both sets at $15 \mathrm{~m}$. Other conditions as in Series 19. Secchi disc, $16 \mathrm{~m}$. at 4.15 p.m.

Series 21. 6.10.'27.

K Photometer. Same locality as Series 19 and 20. Calm. Moderate swell. High water 0.31 a.m. Secchi dise $20 \mathrm{~m}$. in shadow of ship, $16 \mathrm{~m}$. in sun at 9.50 a.m.

Series 22. 14.12.'27.

K Photometer. L used on counter, where it and $\mathrm{K}$ were compared side by side. L used thus, instead of $\mathrm{G}$ on deck-house roof, owing to risk of rain and rough sea. Same locality as Series 19 and 20 . Wind S.W. veering to W. about 2 p.m. Sea rough. High water 9.23 a.m. Secchi disc $13 \mathrm{~m}$. in shadow of ship, $11 \mathrm{~m}$. in sun, at 3.55 p.m.

$\underset{\text { G.M.T. }}{\text { T }} \quad \alpha \quad$ Light

1.26 p.m. $33^{\circ}$ Bright Sun

$1.47, \quad 31$

$1.52, \quad 31$

$2.5, \quad 30$

$2.19,, \quad 29$

2.25, , 28

$2.30,28$

$2.42, \quad 26$

$3.5,24$

$3.39, \quad 20$

$3.54,, \quad 18$

$4.2, \quad 16$

$4.8 \quad, \quad 15$

$4.20,13$

$4.33,12$

4.47 ,
$1.59,, 31$

$3.0 \quad, \quad 24$

,"
",
",
,$"$
,$"$

Bright Sun

,"

,

,

,
12.34 p.m. $35^{\mathrm{c}}$ Bright Sun

12.47 ,

12.53,

$1.18, \quad 33$

1.24 ,

$1.37,31$

$1.51, \quad 30$

2.15 p.m. 28

2.59 , 24

$3.4 \quad, \quad 23$

$3.27, \quad 20$

$3.47,, \quad 18$

3.57 , 17
$1.1, \quad 34$

$1.30, " 32$
B metres

$4 \quad$ r

$3 \cdot 5 \quad 5$

, 10

", 20

, 20
, 25

, 30

," 35

$\begin{array}{ll}3 & 40\end{array}$

$2 \cdot 5 \quad 45$

, 50

$2 \quad 50$

, 55

, 60

i. $\quad 65$

, 20

, 10

$4 \quad \mathrm{c}$

, 10

," 15

, 20

, 25

, 30

$3 \cdot 5 \quad 35$

, 40

$3 \cdot 5$ c

$2 \cdot 5 \quad 20$

, 15

15

30
$" \quad 40$
$\mathrm{V}_{\text {! }}$

m.c.

$\times 10^{3}$

$73 \cdot 3 \quad 73 \cdot 3$

$71 \cdot 0 \quad 18 \cdot 2$

$71 \cdot 8 \quad 11.5$

$71 \cdot 2 \quad 6.78$

$69.5 \quad 3.52$

$66 \cdot 5 \quad 1 \cdot 42$

$65.3 \quad 0.99$

$63.4 \quad 0.725$

$60 \cdot 3 \quad 0.411$

$55 \cdot 2 \quad 0 \cdot 257$

$55 \cdot 6 \quad 0 \cdot 119$

$37 \cdot 0 \quad 0 \cdot 064$

$32 \cdot 9$

$30 \cdot 5$

$27 \cdot 2$

$22 \cdot 6$

$17 \cdot 4$

$13 \cdot 9$

0.053

$0 \cdot 030$

0.012

0.123

$0 \cdot 84$

$2 \cdot 70$

$70 \quad 70$

70

70

71

64

$64 \cdot 5$

62

$61 \cdot 5$

55

44
43

43
$32 \cdot 8$

$28 \cdot 3$

$24 \cdot 2$

$10 \cdot 6$

$5 \cdot 0$

$2 \cdot 52$

$1 \cdot 14$

$0 \cdot 65$

0.356

$0 \cdot 150$

55

0.74

$1 \cdot 35$

1.03

$0 \cdot 143$

0.034 p

$\%$

100

$25 \cdot 6$

$16 \cdot 0$

$9 \cdot 5$

$5 \cdot 1$

$2 \cdot 14$

$1 \cdot 51$

$1 \cdot 14$

$0 \cdot 68$

0.465

$0 \cdot 214$

$0 \cdot 173$

$0 \cdot 161$

$0 \cdot 098$

$0 \cdot 044$

0.545

$4 \cdot 85$

$19 \cdot 4$

100

$15 \cdot 2$

$7 \cdot 0$

$3 \cdot 94$

1.76

1.05

$0 \cdot 577$

$0 \cdot 253$

100

$1 \cdot 68$

$3 \cdot 14$

$3 \cdot 14$

$0 \cdot 505$

$0 \cdot 143$
$21 \cdot 1 \quad 30 \cdot 1$

$\lambda$

$0 \cdot 166$ *

$0 \cdot 099$

$0 \cdot 115$

$0 \cdot 149$

$0 \cdot 121$

$0 \cdot 063$

0.080

$0 \cdot 089$

$0 \cdot 127$

$0 \cdot 108$.

$0 \cdot 108$

$0 \cdot 068$

$0 \cdot 129$

$\overline{0 \cdot 104}$

$0 \cdot 119$

$0 \cdot 172$ *

$0 \cdot 146$

$0 \cdot 135$

0.138

$0 \cdot 133$

$0 \cdot 111$

$0 \cdot 141$

$0 \cdot 196 *$

$0 \cdot 123$

9.22 a.m. $24^{\circ}$ Sun through

9.36 , $26^{\circ}$

$10.21,-30$

$10.28, \quad$,

11.22 "

$11.50, " 35$

12.6 p.m.

$35 \quad$,

12.21 ,

$12.29, ", \quad, \quad$,

$\begin{array}{lrc}1.5 \mathrm{p} . \mathrm{m} . & 15 & \text { Variable } \\ 1.30,, & 14 & , \\ 1.52,, & 13 & , \\ 2.8,, & 12 & , \\ 2.29, & 10 & , \\ 2.44, & 9 & , \\ 2.58,, & 8 & , \\ 3.10,, & 7 & , \\ 3.30,, & 5 & ,\end{array}$

$27 \cdot 7$

$0 \cdot 183$

$0 \cdot 66$

$0 \cdot 121 \pm$

$1.76 \quad 6.25$

$1.96 \quad 5.76$

$0.228 \quad 0 \cdot 66$

$7 \cdot 80 \quad 17 \cdot 2$

$38.3 \quad 84.5$

$2 \cdot 48 \quad 5 \cdot 58$

$0.252 \quad 0.58$

$33 \cdot 7 \quad 81 \cdot 2$

$40 \cdot 8 \quad 100$

$30 \cdot 8 \quad 100$

$\begin{array}{rr}6.4 & 43.5\end{array}$

$4 \cdot 0 \quad 23 \cdot 5$

$1 \cdot 01 \quad 8 \cdot 3$

$0.46 \quad 3.9$

$0.32 \quad 2.6$

$9 \cdot 15$

$29 \cdot 5$

100
$0.130^{+}$

0.134

$0.121 \div$

0.160

$0.137 \ddagger$

0.124

$0 \cdot 128$ *

0.110

$0 \cdot 098$

$0 \cdot 077$

$0 \cdot 111 *$

* In this 21st series of readings separated by considerable time intervals the value of $\lambda$ given is the mean for the layer extending from the surface to the given depth.

$\uparrow$ In these two readings the photometer was not quite level. 
clearing of the water would be reversed, and indicated generally a small increase of $\lambda$ with depth.

It is possible that the vertical movements of the plankton, shown by Russell (6) to be due to variations in illumination, may explain these rather puzzling results. It seems probable that the algal microplankton are most largely concerned in cutting down the light - and they move but little-but the movements of copepods, etc., seem bound to have some effect.

The results are shown graphically in Fig. 3, where the percentage illumination is plotted, unsmoothed, on a logarithmic scale against the depth. Series obtained with photometer $\mathrm{L}$ are shown dotted. There is no evidence of any dependence of the form of the curve on the photometer used. Series 10 is plotted from the means of descending and ascending readings which, in this case, agreed closely. The other series only represent the descending readings, the few ascending ones being omitted for clearness. The relative insensitivity of the photometers with ground-glass windows to oblique light renders them quite unsuitable for the accurate measurement of the loss of light at the sea surface, as the scattering of the light by the surface must alter the average obliquity, and so render the obliquity correction rather uncertain. Moreover, the light just below the surface was generally too unsteady to measure, as the 1927 measurements were for the most part made when there was an appreciable swell. The mean surface transmission recorded in 1925 with a diffusing photometer window was $85 \%$, as measured by the vertical illumination. This value has been assumed in every case in plotting the 1927 results.

It is worth noting that variations in the surface loss are of negligible importance compared with the variations in the absorption coefficient at all depths below 10 metres. Thus if $\lambda=0 \cdot 15$ the absorption in 20 metres of water reduces the illumination to $5 \%$ of its value, while if $\lambda=0 \cdot 20$ the light is reduced to $1.8 \%$. Much larger variations in opacity are common in the sea.

Series 7 and 8, obtained comparatively close inshore, differ from all the later ones in showing very clear surface water and a very large increase in $\lambda$ with depth. It is worth noting that Series 5 , which showed a similar effect, was obtained in 1925 in about the same locality. One may suspect an abundant phytoplankton-or possibly water from Plymouth Sound and its rivers or from the R. Yealm, which is exceptionally rich in fine particles from the china clay works on Dartmoor. This water would probably be above the denser water of the open sea, but the particles in suspension, clumped by the action of the divalent ions present in seawater, might have settled to an appreciable depth, carrying down some of the microplankton and leaving a surface layer of very clear water. 


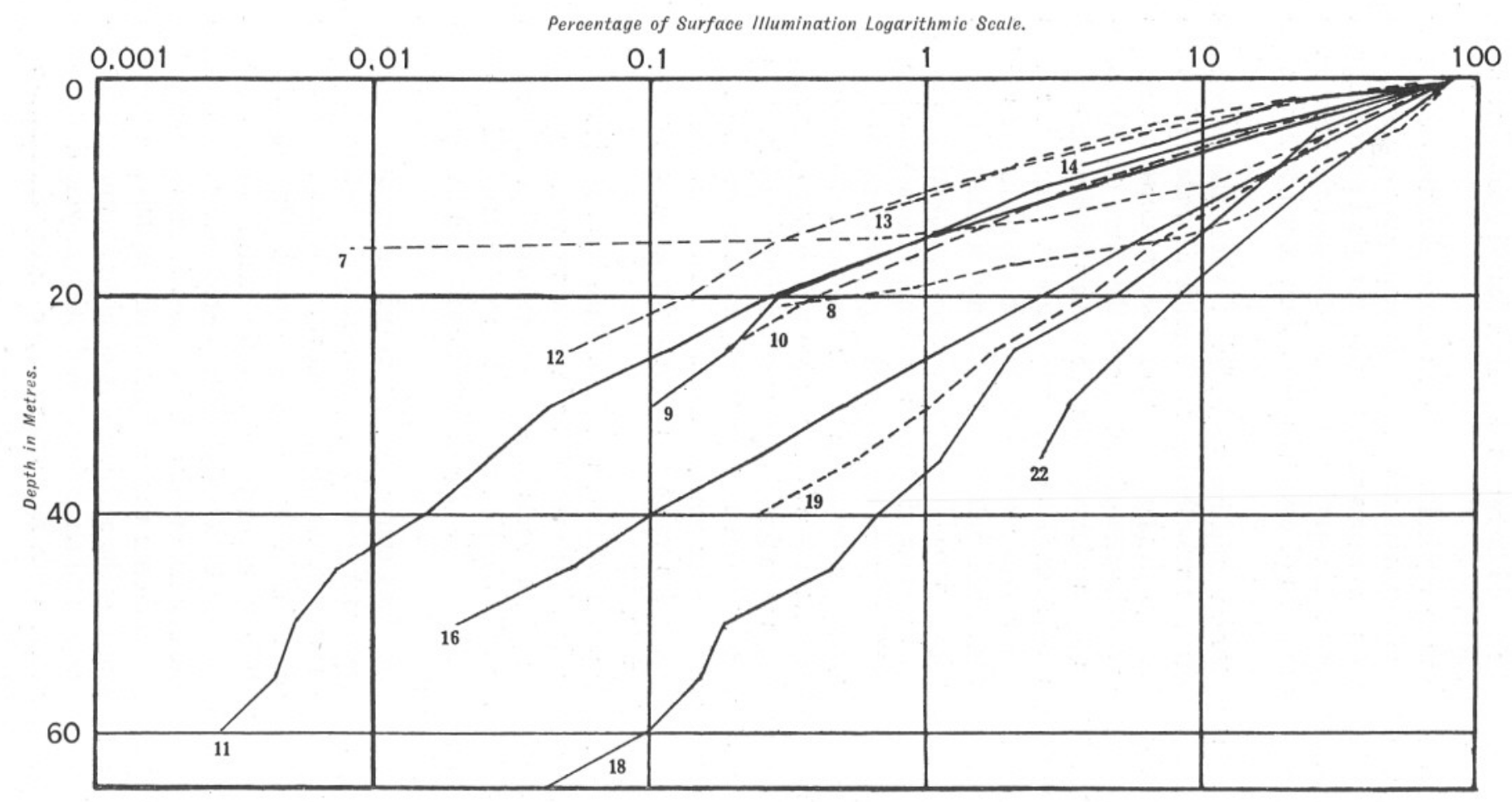

FIG. 3.-The ordinates show depths in metres. The percentage of the surface illumination is shown (logarithmic scale) on the abscisse. The series numbers are given beside each curve. Where photometer $\mathrm{L}$ was used the line is dotted, a full line being used for $\mathrm{K}$. Note the increased steepness of the curves as the serial numbers rise-showing the progressive clearing of the water from September to December. 
Series 9 to 12 were obtained on September 5th and 7 th at E1. They agree well, except that Series 12 shows somewhat greater absorption than the others in the surface layers.

There was a temperature break at 20 metres, temperature $15 \cdot 1$, with 13.83 at $25 \mathrm{~m}$. and 13.36 at $70 \mathrm{~m}$. At $15 \mathrm{~m}$. it was 15.76 and 16.1 at the surface.

Series 13 and 14, obtained in Cawsand Bay with a flood tide, agree fairly well with each other and with the surface results found two days before at E1. Series 14 could not be carried below 8 metres, since at 10 metres the photometer apparently became intermittently shaded by weeds. This is rather surprising, as it was still 5 or 6 metres above the uneven rocky bottom; but as it occurred shortly after high water it is possible that the slackness of the tide enabled long streamers of Laminaria spp., or perhaps Chorda, to reach up to this level.

Series 15 to 17 were obtained with a strong offshore wind. The temperature at $5 \mathrm{~m}$. was $15 \cdot 2^{\circ} \mathrm{C}$., falling to $14 \cdot 3^{\circ}$ at $25 \mathrm{~m}$., and $14 \cdot 2^{\circ}$ at $45 \mathrm{~m}$., showing that at this site vertical mixing had already taken place, though it is not noticeable at E1 till later, as a rule. This is shown in the approximate uniformity of the absorption coefficient in 16, which closely resembles some of the 1925 series.

These three series enable some idea to be obtained of the angular distribution of the submarine light. A comparison of Series 15 and 16 shows that the reading of the photometer with the window vertical averaged about $0 \cdot 14$ of the reading at the same depth with the window horizontal.

This ratio was approximately independent of the depth, the variations being no larger than would be expected, since there was no means of insuring that the azimuth of the photometer remained constant in Series 15. The photometer in the above-water set was facing towards the sun, so the value of $\mathrm{p}_{\mathrm{h}}$ in air is about what one would expect. In deducing the submarine illumination from the photometer readings in Series 15 and 17 the same obliquity factor has been used as in the other series. This certainly gives too low results for both the horizontal and the upward illuminations, since, in both cases, the average obliquity of the light, relative to the photometer window, must considerably exceed that for the normal position.

We can calculate the horizontal illumination just below a smooth water surface, lit by a uniform sky, by a method similar to that already described (2, p. 183) for finding the vertical illumination under these conditions, remembering that, as the horizontal illumination is equally distributed in all azimuths, a plane vertical surface will only receive $\frac{1}{\pi}$ of the whole. We find that the illumination on a vertical surface comes out as $0 \cdot 19$ of NEW SERIES.-VOL. XV. No. 2. APrIL, 1928. 
the vertical illumination on a horizontal surface. We have seen that the average ratio recorded by the photometer is $0 \cdot 14$, and that the photometer certainly under-estimates the horizontal light. Probably the photometer reading represented rather more horizontal light than that given above for the ideal case.

It appears, then, that the angular distribution of the submarine light does not differ very greatly from that for the above conditions, and that we may use the obliquity factor appropriate to them in finding the vertical illumination, without introducing any large error. Moreover, since the distribution seems to be almost independent of the depth, any such error will affect all the submarine readings equally, so that it will not affect the value of $\lambda$. It will, however, seriously affect our estimate of surface loss, so that, to find this, a photometer with a perfect diffusing window, as used in our earlier measurements, appears to be essential.

Since, in the various series, $\lambda$ seems to be almost independent of the altitude of the surface light, ${ }^{*}$ we may assume that the angular distribution of the submarine light (which evidently affects the value of $\lambda$ ) is also almost independent of the altitude of the surface light.

The fact that the average angle of illumination appears to be almost independent of the depth is readily explained. The effect of absorption is to enhance the proportion of high-angle light, while that of scattering is just the reverse. At a moderate depth the average obliquity should attain a value such that these effects balance. Below this the obliquity should remain constant, unless the ratio of the scattering and absorption effects altered with depth.

In Series 17 the upward illumination was about $1.3 \%$ of the downward at the same depth in Series 16, showing a tendency to relative increase with depth.

The remaining series show clearly the great increase in the clearness of the water which occurred with the approach of winter. If we except the remarkably clear surface water found in Series 7 and 8 the effect is most marked in the upper layers.

The effect of this reduction in opacity is also shown in Table III, where the illuminations recorded at different depths on four different dates are given in metre candles. As the surface light generally varies considerably during a series, the submarine illuminations have all been reduced to the value corresponding to the mean surface light for the series which is shown opposite to the letter a in the depth column.

* Series 21 was specially carried out to test this point. 
TABLE III.

$\begin{array}{ccccc}\begin{array}{c}\text { Series No. } \\ \begin{array}{c}\text { Depth in } \\ \text { metres. }\end{array}\end{array} & \begin{array}{c}11 \\ \text { September 7. }\end{array} & \begin{array}{c}16 \\ \begin{array}{c}\text { September 12. } \\ \text { Vertical Illumination in }\end{array}\end{array} \begin{array}{c}18 \\ \begin{array}{c}\text { October 3. } \\ \text { Metre Candles. }\end{array}\end{array} & \begin{array}{c}22 \\ \text { December } 14 .\end{array} \\ 5 & 88,000 & 45,000 & 56,000 & 14,000 \\ 10 & 15,200 & 15,400 & 14,300 & 6,100 \\ 15 & 3,430 & 6,250 & 9,000 & 3,280 \\ 20 & 815 & 2,700 & 5,300 & - \\ 25 & 239 & 1,240 & 2,850 & 1,160 \\ 30 & 103 & 513 & 1,200 & - \\ 35 & 39 \cdot 5 & 225 & 845 & 460 \\ 40 & 24 & 102 & 640 & 364 \\ 45 & 12 & 46 \cdot 5 & 380 & \\ 50 & 6 \cdot 5 & 23 \cdot 5 & 260 & \\ 55 & 5 & & 108 & \\ 60 & 4 & & 90 & \\ 65 & 2 \cdot 5 & & 55 & \\ & & & 24 \cdot 5 & \end{array}$

The variation in opacity is shown in Fig. 4, where $\lambda$ is plotted against the depth. The curves are numbered to correspond with the series from which these are derived. Some of them represent the means of two or more series obtained under approximately similar conditions of time and place.

\section{Comparison with the 1925 Results.}

Series 2 and 5 were obtained just before, and just after, low water on September 2 and 3, 1925, in about the same locality as Series 7 and 8. The latter were obtained during the last three hours' ebb on September 2, 1927. The opacity of the surface water was very similar in the four series, but in Series 2 this remained almost constant down to at least $30 \mathrm{~m}$., while in Series 5, 7, and 8 it showed large, and comparatively sudden, increases at about $25 \mathrm{~m} ., 5 \mathrm{~m}$., and $10 \mathrm{~m}$., respectively. In the case of Series 5, which was obtained on a rough day, this was attributed to material derived from the bottom, but this could not be the explanation of the effects found in Series 7 and 8 . It is possible that the effect may, in all cases, have been due to the presence of harbour or river water, though, if so, it is rather surprising to find it underlying a layer of very clear water. A suggested explanation has already been given.

Series 13 and 14 showed considerably greater surface opacity than 
Series 1, 3, and 4, which were also obtained in Cawsand Bay, though under somewhat different conditions.

Series 9 to 12 are not comparable with any of the 1925 results, as the first obtained at E1 was Series 6, on October 1, 1925. This may be compared with Series 18 (October 3, 1927), which gave about the same surface opacity, but differed from the earlier series in showing a decrease

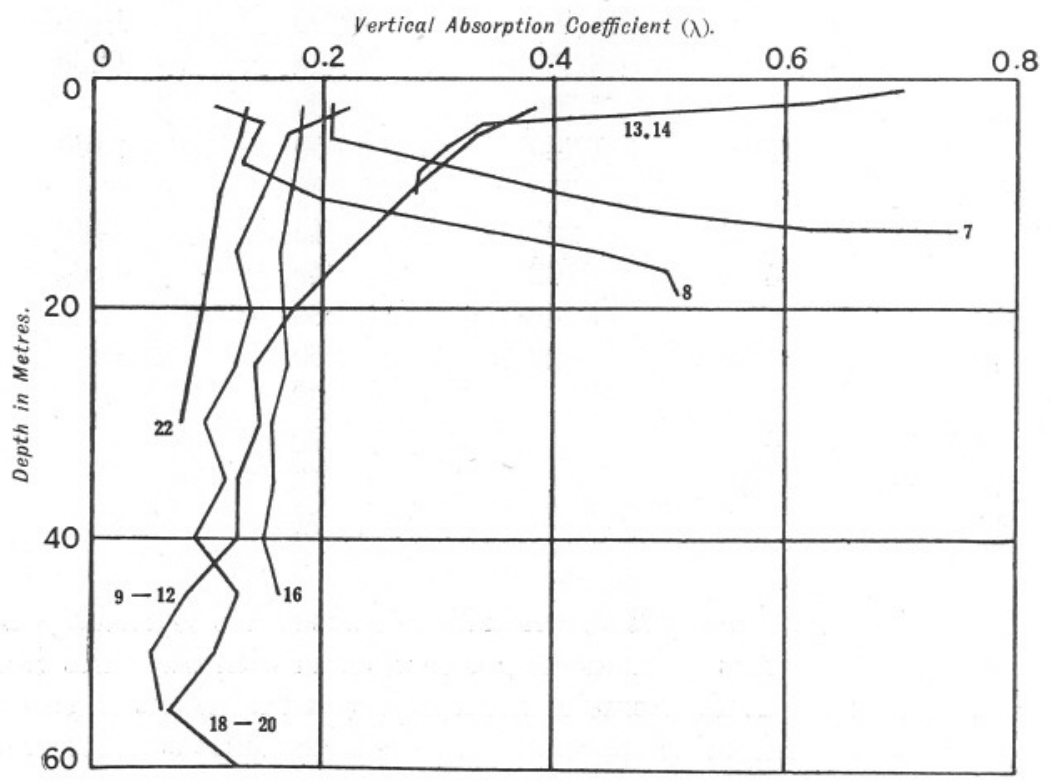

Fig. 4.-The ordinates show depths in metres against which values of the vertical absorption coefficient, $\lambda$, are plotted on the abscissæ.

with depth, instead of a slight increase. The differences are probably due to variations in the distribution of the phytoplankton-or even of the zooplankton.

The other series are not comparable, as regards conditions, with any of the earlier ones.

\section{Observations with the SeCchi Disc.}

Table IV gives an attempt to correlate some observations made with a Secchi disc at about the same times as some of the series. Here $d$ is the depth in metres at which the disc was just visible. Where observations were taken in the shadow of the ship they are indicated by an asterisk in the depth column. $V_{\mathrm{a}}$ is the estimated value of the surface illumination in thousands of metre candles, and $\mathrm{p}$ the percentage illumination at the limit of visibility as estimated from the corresponding series. $\mathrm{V}$ is the corresponding illumination on the disc at that depth. 
TABLE IV.

\begin{tabular}{|c|c|c|c|c|c|c|}
\hline Series. & Date. & $\mathrm{T}$ & d & $\begin{array}{c}V_{\mathrm{a}} \\
\mathrm{m.c} . \\
\times 10^{3}\end{array}$ & $\begin{array}{l}\underset{p}{\mathrm{~m} . c .} \\
\times 10^{3}\end{array}$ & V \\
\hline 11 & $7 / 9 / 27$ & 0.15 p.m. & 8 & 100 & 8 & 8 \\
\hline & " & ", & $8^{*}$ & \multicolumn{2}{|c|}{$\leq$} & $"$ \\
\hline 16 & $12 / 9 / 27$ & 3.0 p.m. & $9 \cdot 5$ & 40 & $14 \cdot 5$ & $5 \cdot 6$ \\
\hline 18 & $3 / 10 / 27$ & 5.0 p.m. & $15^{*}$ & 10 & $9 \cdot 5$ & 0.95 \\
\hline 20 & $5 / 10 / 27$ & 4.15 p.m. & 16 & 20 & 3 & $0 \cdot 6$ \\
\hline 21 & $6 / 10 / 27$ & 9.50 a.m. & 16 & 30 & 8 & $2 \cdot 4$ \\
\hline , & , & , & $20 *$ & ", & 6 & $1 \cdot 8$ \\
\hline 22 & $14 / 12 / 27$ & 3.55 p.m. & 11 & 4 & 21 & 0.8 \\
\hline ", & , & ", & $13^{*}$ & ", & $17 \cdot 5$ & $0 \cdot 7$ \\
\hline
\end{tabular}

It is evident that both the absolute and the percentage values of the illumination at which the disc was just visible varied widely. This was probably due to variations in the surface which would probably have a greater effect on the visibility of the disc than on the illumination. It seems probable that the use of a water telescope might lead to more consistent results.

\section{SUMMARY AND CONCLUSIONS.}

Further measurements have been made of the penetration of daylight into the sea near Plymouth, photometers containing both vacuum and gas-filled photo-electric cells being used. The effect of obliquity of illumination on the sensitivity of these photometers was large, and has been allowed for as far as possible. The sensitivity of the vacuum cell used in the sea attained its maximum at a wave length of about $4,050 \AA$ A.U., that of the gas-filled cell at about 4,350. The sensitivity of both to wave lengths greater than 5,500 was small.

The following tentative conclusions have been reached :-

1. For depths down to about 40 metres, in clear water, the vacuum type is the more convenient, owing to its constancy.

2. When suitable corrections are applied the results obtained with the gas-filled cell approximate closely to those found under similar conditions with the vacuum cell. Its much greater sensitivity enables measurements to be made at greater depths. By altering the voltage applied a very wide range of illumination can be measured, the maximum found being 109,500 metre candles, and the minimum read at 60 metres being $2 \cdot 5$ metre candles. 
3. The effect of the variations in the surface loss of light is apparently negligible compared with that of variations in opacity.

4. The altitude of the surface light has but little effect on the penetrating power of the light in the water, since the average altitude of the latter depends chiefly on a balance between the opposing effects of absorption and scattering. There is some evidence that the average altitude of the light in the water at depths below 10 metres is between $50^{\circ}$ and $60^{\circ}$.

5. The opacity of the water generally decreases with increase of depth, though the opposite is sometimes true, as was found in the earlier experiments. It is suggested that the variation is due to the different horizontal distribution of the phytoplankton, and to the zooplankton ascending or descending according to the movement of the optimum light intensity for each species.

6. The opacity decreased with the advent of winter to such an extent that measurements in December showed more light at all depths below 10 metres than was found on several occasions early in September. Correspondingly, the sea is far poorer in plankton in December than in September.

The absorption coefficients found varied from 0.62 to 0.051 in the open sea at various seasons, places and depths.

7. Attempts to correlate the maximum depth of visibility of a Secchi disc with either the absolute or the percentage illumination at that depth were unsuccessful.

The authors desire to acknowledge their indebtedness and to express their thanks as follows: To the Marine Biological Association for the greater part of the apparatus used at sea, also for laboratory and seagoing facilities; to the Royal Dublin Society for laboratory facilities; to Prof. W. E. Thrift for the loan of apparatus used at sea and for apparatus from the Physical Laboratory, Trinity College, Dublin, used in standardising; to Prof. J. Joly for the loan of the amplifier; and to the Government Grant Committee of the Royal Society for apparatus, especially photo-electric cells also used in work on illumination in relation to plant distribution ashore, for which the grant was given. The authors also desire to express their thanks to Capt. V. Lord and the crew of the Salpa for their whole-hearted assistance in the handling of the gear, without which the work could not have been carried out. Our thanks are also due to the Staff of the Research Laboratories of the General Electric Co., Wembley, for preparing a special photo-electric cell and for their advice. 


\section{REFERENCES.}

1. Poole, H. H. On the Photo-electric Measurement of Submarine Illumination. Sci. Proc. R. Dublin Soc., 1925, 18, No. 9, 99-115.

2. Poole, H. H., and Atkins, W. R. G. On the Penetration of Light into Sea-water. Journ. Marine Biol. Assoc., 1926, 14, No. 1, 177-198.

3. Atkins, W. R. G. A Quantitative Consideration of some Factors concerned in Plant Growth in Water. Pt. I. Some Physical Factors. Journ. du Conseil Internat. pour l'Exploration de la Mer, 1926, 1, No. 2, 99-126.

4. Forrest, J. F. The Electric Arc as a Standard. Electrician, 1913, '1, 729 and 1007.

5. Allen, N. A. The Current Density in the Crater of the Carbon Arc. Proc. Phys. Soc. (London), 1921, 33, Pt. 2, 62-69.

6. Russell, F. S. The Vertical Distribution of Marine Macroplankton. Pt. V. Journ. Marine Biol. Assoc., 1927, 14, 557-608, and earlier Parts in same Journal. 
I I- 